Año 9. Núm. 24 (Edición especial Julio- diciembre 2016)

http://revistainvestigacionacademicasinfrontera.com
Revista de Investigación

Académica sin Frontera

ISSN: 2007-8870

\title{
EMBARGO, REMATE Y/O ADJUDICACIÓN DE BIENES, EN LA RELACIÓN JURÍDICO-TRIBUTARIA EN MEXICALI
}

\author{
Emigdio Julián Becerra Valenzuela \\ Sergio Gilberto Capito Mata \\ Elizabeth García Espinoza
}

\section{RESUMEN}

El presente trabajo de investigación se plantea dentro de un marco jurídico, social e institucional, ya que la magnitud de éste comprende la actuación de la Administración Desconcentrada de Recaudación de Baja California "1" respecto del embargo, remate y/o adjudicación de bienes muebles e inmuebles propiedad de terceros ajenos a la relación jurídico-tributaria, por lo que para su diagnóstico constitucional, se necesita y requiere de una investigación científica y metodológica de las unidades de observación, con la finalidad de ofrecer mecanismos de perfeccionamiento de procedimientos recaudatorios en los que se observe a plenitud los derechos humanos y así evitar futuras sentencias que afecten y mermen al erario.

Los resultados que se muestran, derivan de una investigación básica y práctica, en donde se realizaron encuestas y entrevistas que nos proporcionan datos y cifras, que ayudan al mejoramiento de procedimientos y mecanismos recaudatorios en las 


\section{http://revistainvestigacionacademicasinfrontera.com}

unidades administrativas del Servicio de Administración Tributaria, también, brinda orientación a los contribuyentes sobre sus derechos y obligaciones tributarias.

Por lo tanto a modo de conclusión, podemos decir que el Servicio de Administración Tributaria debe de actualizar y capacitar tanto a su personal, como los manuales internos que se aplican en el Procedimiento Administrativo de Ejecución.

Palabras clave: remate y adjudicación de bienes muebles e inmuebles, Procedimiento Administrativo de Ejecución, créditos fiscales firmes.

\section{INTRODUCCIÓN}

El presente ensayo, es el resultado del proceso investigativo y de análisis constitucional del embargo, remate y adjudicación de bienes muebles e inmuebles propiedad de terceros ajenos a la relación jurídico-tributaria, dentro del Procedimiento Administrativo de Ejecución realizado por la Administración Desconcentrada de Recaudación de Baja California "1" tendientes a hacer efectivos créditos fiscales firmes y exigibles de los contribuyentes.

A continuación se muestran los resultados, datos y cifras obtenidos del censó que se realizó a todos y cada uno de los abogados tributarios adscritos a la Administración Desconcentrada de Recaudación de Baja California "1", y a la totalidad de los abogados dictaminadores de la Administración Desconcentrada Jurídica de Baja California "1"; la acción que se llevó a cabo para la obtención de la autorización de aplicación del censo, fue una entrevista previa con los licenciados Luis Jonathan Gómez Jiménez y Rosendo Heliodoro Guzmán García, subadministradores de las unidades administrativas antes mencionadas; el instrumento aplicado cuestiona principalmente los conocimientos de los siguientes temas: funciones de la Administración Desconcentrada de Recaudación, Procedimiento 
Año 9. Núm. 24 (Edición especial Julio- diciembre 2016)

http://revistainvestigacionacademicasinfrontera.com $\frac{\cos }{3}$

Revista de Investigación

Académica sin Frontera

ISSN: 2007-8870

Administrativo de Ejecución, Garantía de Audiencia y la Reforma Constitucional en Materia de Derechos Humanos.

Así púes, el objetivo principal del trabajo que se desarrolla, lo constituye el hecho de resaltar las áreas de oportunidad que se detectaron al investigar el Procedimiento Administrativo de Ejecución que despliega los abogados tributarios adscritos a la Administración Desconcentrada de Recaudación de Baja California "1", con la finalidad de brindar opiniones y orientaciones desde el punto de vista teórico y práctico, que sirvan para el mejoramiento continuo de los procesos recaudatorios de las unidades administrativas del Servicio de Administración Tributaria, así como también, que sea un instrumento de apoyo a los contribuyentes respecto de sus derechos y obligaciones de naturaleza fiscal.

\section{DESARROLLO}

\section{a) NOCIONES DE LA ACTIVIDAD FINANCIERA DEL ESTADO}

El presente análisis, se desenvuelve dentro del campo de acción del Derecho Financiero, por lo cual su entendimiento y comprensión resulta de trascendencia para su desarrollo, por ese motivo se cita el concepto que Raúl Rodríguez Lobato da del mismo, señala que el Derecho Financiero se entiende "como la disciplina que tiene por objeto el estudio sistemático de las normas que regulan los derechos económicos del Estado y de los demás entes públicos que emplean para el cumplimiento de sus fines, así como el procedimiento jurídico de percepción de los ingresos, ordenación de los gastos y realización de los gastos que se destinan a cumplir la función del Estado" (Rodríguez Lobato, 2006), por su parte el jurista Joaquín B. Ortega define la Actividad Financiera del Estado "como el instrumento de procurarse los medios necesarios para los gastos públicos destinados a la satisfacción de las necesidades públicas y en general a la realización de sus propios fines" (De la Garca, 2005), bajo las premisas anteriores, podemos señalar, que al 
Año 9. Núm. 24 (Edición especial Julio- diciembre 2016)

\section{http://revistainvestigacionacademicasinfrontera.com}

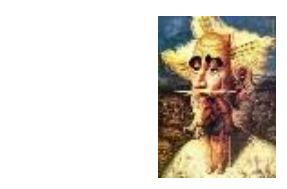

Revista de Investigación

Académica sin Frontera ISSN: 2007-8870

constituir el Procedimiento Administrativo de Ejecución un instrumento coactivo, imperativo y recaudatorio por excelencia con el que cuenta el Estado Mexicano para hacerse llegar ingresos que le permitan la satisfacción de las necesidades individuales, colectivas y sociales del país, el mismo debe de estar protegido por normas financieras y políticas públicas que vayan encaminadas a su perfeccionamiento y actualización, que le concedan al gobernado una mayor certeza jurídica respecto de los destinos de sus contribuciones y a la vez, un instrumento ágil y confiable que le conceda al Estado una legitimidad suficiente y bastante para su instauración.

Ahora bien, estos conceptos tienen un vínculo estrecho con lo que conocemos como hacienda pública, la cual a través del tiempo se ha "definido como el estudio de las leyes por las cuales los hombres satisfacen las necesidades públicas" (Astudillo, 2002), bajo este contexto se considera oportuno señalar que en los últimos años el gobierno federal a través de la Secretaria de Hacienda y Crédito Público en coordinación con su órgano desconcentrado denominado Servicio de Administración Tributaria, han implementado políticas económicas tendientes a mejorar la actividad recaudatoria del estado, con la finalidad de satisfacer las múltiples necesidades que tiene el estado mexicano, así mismo no pasa desapercibido que a la fecha se encuentra pendiente de resultados la llamada Reforma Fiscal, que busca, de acuerdo a sus postuladores, una mayor y eficiente recaudación, con políticas tendientes a evitar la evasión de impuestos.

En nuestro país el Servicio de Administración Tributaria, tiene "la responsabilidad de aplicar la legislación fiscal y aduanera, con el fin de que las personas físicas y morales contribuyan de manera proporcional y equitativa al gasto público; así mismo cuenta con la facultad de fiscalizar a los contribuyentes para que cumplan con las disposiciones tributarias y aduaneras; de igual manera tiene la responsabilidad de facilitar e incentivar el cumplimento voluntario, así como generar 
Año 9. Núm. 24 (Edición especial Julio- diciembre 2016)

http://revistainvestigacionacademicasinfrontera.com

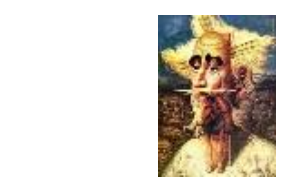

Revista de Investigación

Académica sin Frontera ISSN: 2007-8870

y proporcionar la información necesaria para el diseño y la evaluación de la política tributaria" (Ocampo Medina, 2012), de allí que resulte oportuno, diagnosticar y opinar sobre los procedimientos utilizados por sus unidades administrativas al momento del cobro y recaudación de los tributos.

Así mismo, es de señalarse que unas de las políticas públicas puesta en marcha en los últimos años por el gobierno federal, lo constituye el lado ético-moral de las autoridades y organismos recaudatorios, con el fin de erradicar de la percepción del contribuyente que existe de un sistema tributario corrupto, ineficiente y sesgado al interés de ciertos grupos, "por esa razón el Servicio de Administración Tributaria trabaja día con día para mejorar su reputación e imagen pública, por lo que ha hecho suyo los valores que se traducen como la honestidad, respeto, compromiso y responsabilidad" (Domingo Hernández, 2004), por lo cual, resulta más que apremiante que los abogados dictaminadores y los abogados tributarios conozcan al pie de la letra la Reforma Constitucional en materia de Derechos Humanos.

\section{b) El Procedimiento Administrativo de Ejecución}

Es importante resaltar que la relación jurídico-tributaria que existe entre los contribuyentes y el fisco se crea un ciclo tributario, que se inicia desde que el contribuyente se coloca en algunos de los supuestos previstos en la ley; una vez que se emite una resolución determinante, la misma se remite a la Administración Desconcentrada de Recaudación del Servicio de Administración Tributaria de la localidad del domicilio fiscal del contribuyente para alguno de los siguientes efectos: a) notificación, control y cobro, b) control y cobro, c) control; en el primer supuesto se realiza una vez que la autoridad administrativa emite una resolución determinante sin que sea ella la que proceda a notificar, por ejemplo las que se derivan del Procedimiento Administrativo en Materia Aduanera; el segundo supuesto identificado con inciso B), se actualiza cuando las autoridades liquidatarias ya 


\section{http://revistainvestigacionacademicasinfrontera.com}

procedieron a dar a conocer al contribuyente el contenido de dicha resolución, por ejemplo las que emiten la Comisión Nacional del Agua, y el tercer supuesto aparece principalmente cuando el contribuyente ya procedió a pagar, en este supuesto no se actualiza al Procedimiento Administrativo de Ejecución.

Ahora bien, el Procedimiento Administrativo de Ejecución tiene su respaldo en primer lugar, en el artículo 14 de la Constitución Política Federal, de donde se desprende que "para privar de las propiedades, posesiones o derechos a los particulares, se deben de cumplir las formalidades esenciales del procedimiento administrativo respectivo y conforme a las leyes expedidas con anterioridad al mismo" (Sánchez Gómez, 2011), de allí que se derive que las unidades recaudatorias deben de respetar en su integridad las formalidades esenciales a saber: la notificación del inicio del procedimiento y sus consecuencias al individuo, la oportunidad de ofrecer y desahogar pruebas en que se finque la defensa, la oportunidad de alegar, y el dictado de una resolución que dirima las cuestiones debatidas (Formalidades Esenciales del Procedimiento. Son las que garantizan una adecuada y oportuna defensa previa al acto privativo., 1995).

De igual manera el artículo 16 del mismo ordenamiento jurídico, establece la esencia de las formalidades constitucionales que deben seguirse en todo procedimiento, al ordenar que nadie puede ser molestado en su persona, familia, domicilio, papeles o posesiones, sino en virtud de mandamiento escrito de la autoridad competente, que funde y motive la causa legal del procedimiento.

Ahora bien, el fundamento constitucional del Procedimiento Administrativo de Ejecución se encuentra en el Artículo 22, mismo que no considera como confiscación de bienes a la aplicación total o parcial de los bienes de una persona hecha por la autoridad para el pago de impuestos mediante el cobro forzado, facultando a favor de la autoridad el secuestro y remate de bienes suficientes del contribuyente para cubrir el crédito fiscal y sus accesorios. 
http://revistainvestigacionacademicasinfrontera.com

Es importante señalar que las facultades de la Administración General de Recaudación, las encontramos contempladas en el artículo 16 del Reglamento Interior del Servicio de Administración Tributaria publicado el 24 de Agosto de 2015, en donde se desprende el desarrollo y aplicación de la actividad económica coactiva del Estado.

Los presupuestos para la actualización del Procedimiento Administrativo de Ejecución son los siguientes:

1. La existencia de un crédito fiscal que no ha sido satisfecho dentro del plazo que el Código Fiscal de la Federación señala para tales efectos, Artículo 65.

2. La invasión por parte de la autoridad ejecutora de la esfera jurídica del deudor, mediante la afectación de su patrimonio ya sea en una cantidad de dinero o de otros bienes para satisfacer coactivamente el crédito fiscal.

3. La satisfacción del interés de la Administración a título de acreedor, mediante el ingreso de la cantidad de dinero que se le debía o bien mediante la adjudicación de bienes a su favor.

A continuación se muestra gráficamente las principales etapas del Procedimiento Administrativo de Ejecución para una mejor apreciación del lector: 
Año 9. Núm. 24 (Edición especial Julio- diciembre 2016)

http://revistainvestigacionacademicasinfrontera.com

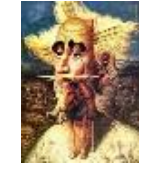

Revista de Investigación Académica sin Frontera ISSN: 2007-8870

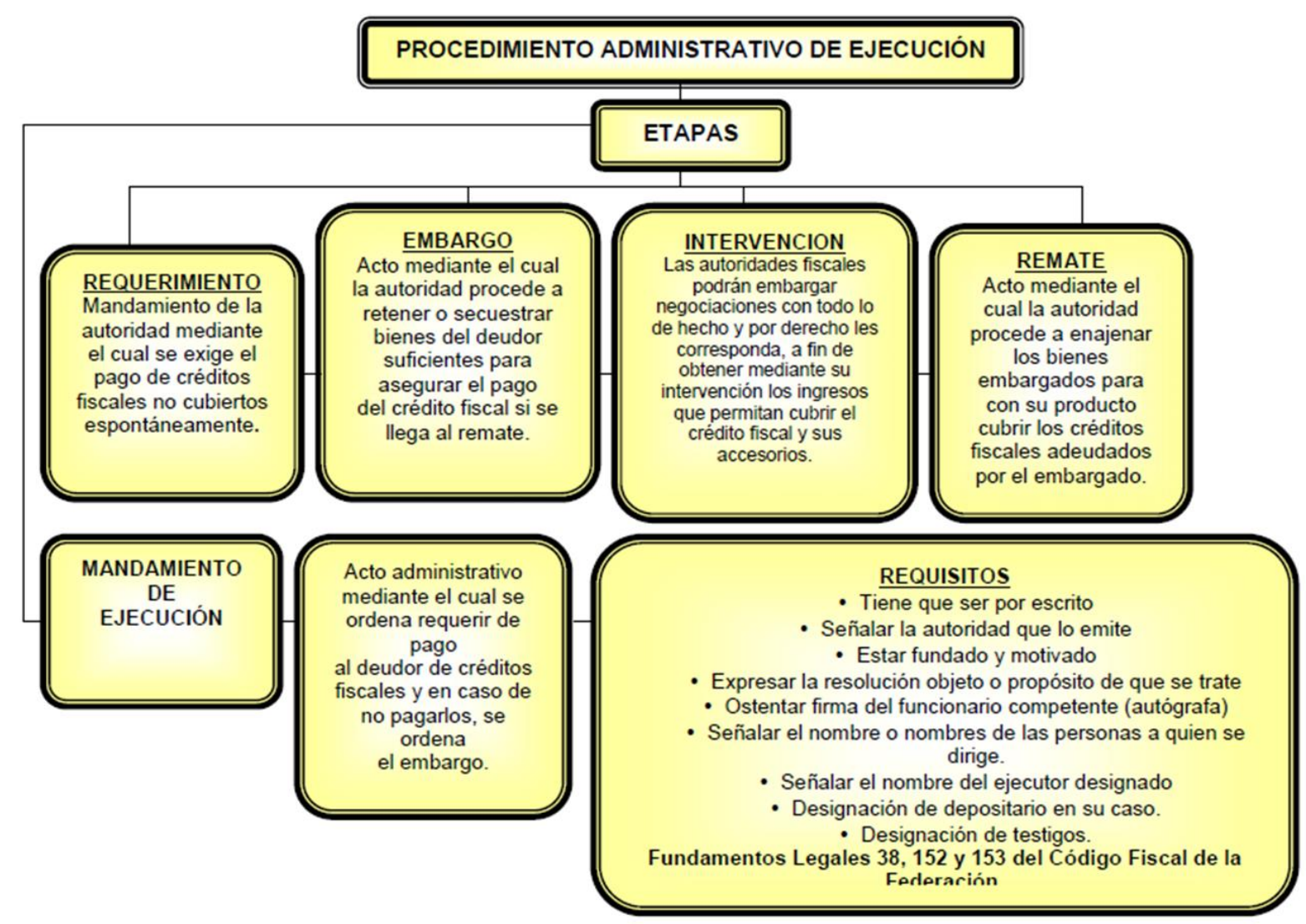

Todas esas fases, están encaminadas a la satisfacción del cobro de contribuciones a favor del fisco federal.

c) Conceptos de violación frecuentes contra el embargo, remate y adjudicación de bienes muebles e inmuebles propiedad de terceros ajenos a la relación jurídico-tributaria.

Antes de iniciar con el estudio de los conceptos de violación, hechos valer por terceros extraños a la relación jurídico-tributaria respecto al embargo, remate y/o adjudicación de bienes muebles e inmuebles de su propiedad; es procedente establecer el concepto de tercero extraño, el cual el Poder Judicial de la Federación lo ha establecido de la siguiente manera: persona extraña es, en principio, "aquella 


\section{http://revistainvestigacionacademicasinfrontera.com}

que no ha figurado en el juicio o en el procedimiento como parte en sentido material, pero que sufre un perjuicio dentro del mismo o en la ejecución de las resoluciones, sin haber tenido la oportunidad de ser oída en su defensa por desconocer las actuaciones relativas, quedando incluida en este concepto, asimismo, la parte que no fue emplazada a que fue emplazada incorrectamente" (Persona Extraña a Juicio, Concepto de., 1998).

Seis años de trabajar en el Servicio de Administración Tributaria, en la coordinación de amparos e instancias judiciales, nos legitiman para señalar que los terceros ajenos a la relación jurídico-tributaria hacen valer esencialmente como conceptos de violación los siguientes:

* Los quejosos aducen que se violan en su perjuicio las garantías tuteladas en los artículos 14 y 16 constitucionales, debido a que se les está privando de su propiedad, consistente en inmuebles, sin mediar juicio en el cual se siguieran las formalidades esenciales del procedimiento, es decir, no ha sido oído ni vencido en juicio, ya que no es parte en el procedimiento administrativo de ejecución, en los cuales se embargó y enajeno el cincuenta por ciento de dichos bienes inmuebles, respecto de los cuales la quejosa es ajena.

* Los quejosos aducen esencialmente como motivo de la adjudicación de bienes inmuebles que, se violan en su perjuicio las garantías tuteladas en los artículos 14 y 16 constitucionales, debido a que no son llamadas al procedimiento de ejecución de origen, dejándolos con ello en estado de indefensión al no poder comparecer al procedimiento de ejecución para hacer valer sus derechos, no obstante de existir el derecho real que posee sobre el inmueble adjudicado que está inscrito ante el Registro Público de la Propiedad y del Comercio, siendo la peticionaria del amparo acreedora 


\section{http://revistainvestigacionacademicasinfrontera.com}

Revista de Investigación

Académica sin Frontera ISSN: 2007-8870

preferente ante la autoridad fiscal, razón por la cual se le debió llamar al aludido procedimiento.

* Los quejosos aducen que se violan en su perjuicio las garantías de audiencia y legalidad y toda vez que son ilegalmente desposeídos de un bien mueble de su propiedad en virtud de los procedimientos administrativos iniciados con motivo del cobro de algunos créditos fiscales en contra de una persona diferente al suscrito y en un procedimiento en el que no han sido oído ni vencido, además de no ser parte procesal del mismo, siendo ya extraño al proceso y en lo que a ellos respecta no se les han cumplido con las formalidades esenciales del procedimiento ni se funda ni motiva la causa legal del mismo, puesto que la resolución que recaiga al juicio, de donde emanan los actos reclamados, solo beneficia o perjudica un tercero extraño al litigio planteado, violentando mis Derechos Humanos, como es el caso, que se vulneran en perjuicio los artículos 14 y 16 de la Constitución General de la República.

De lo anterior trascrito, resulta evidente que los quejosos aducen medularmente que se amedrentan en su perjuicio sus derechos humanos contemplados en los artículos 14 y 16 de la Constitución Política de los Estados Unidos Mexicanos, en virtud de que se les priva de su propiedad sin las formalidades esenciales del procedimiento y sin un documento en donde se funde y motive la causa legal del procedimiento.

Al respecto no hay que perder de vista que el 10 de Junio de 2011, fueron publicadas en el Diario Oficial de la Federación, reformas en materia de Derechos Humanos, modificándose el artículo 1 de nuestra carta magna, lo anterior como resultado de la sentencia emitida en fecha 23 de Noviembre de 2009 por la Corte Interamericana de Derechos Humanos relacionada con caso Rosendo Radilla vs Los Estados Unidos Mexicanos, ahora el artículo 1 establece que todas las 
Año 9. Núm. 24 (Edición especial Julio- diciembre 2016)

http://revistainvestigacionacademicasinfrontera.com
Revista de Investigación

Académica sin Frontera ISSN: 2007-8870

autoridades, en el ámbito de sus competencias, tienen la obligación de promover, respetar, proteger y garantizar los derechos humanos de conformidad con los principios de universalidad, interdependencia, indivisibilidad y progresividad, lo que engendra la obligación al Estado Mexicano de prevenir, investigar, sancionar y reparar las violaciones a los derechos humanos, en los términos que establezca la ley.

Por lo anterior, resulta claro que la autoridad recaudadora, al momento de desplegar el Procedimiento Administrativo de Ejecución, debe de observar a plenitud el marco normativo vigente, además de aplicar estrictamente los postulados de la Constitución Política Federal, en el sentido de valerse de las formalidades esenciales del procedimiento y observar los derechos humanos de los ciudadanos conforme a su interpretación más amplia.

\section{d) Obtención de Datos y resultados de la investigación.}

Para el registro y obtención de información se elaboraron dos cuestionaros, el primero de ellos destinado a los Abogados Tributarios adscritos a la Administración Desconcentrada de Recaudación "1" de Baja California, y el segundo fue preparado para los Abogados Dictaminadores de la Administración Desconcentrada Jurídica "1" de Baja California, dichos cuestionarios fueron elaborados con preguntas literales, abiertas, parcialmente estructuradas, estructuradas y de selección, como preámbulo se estableció una breve presentación e instrucciones, lo anterior con la finalidad de sensibilizar al censado en la participación imparcial y objetiva en la presente investigación.

Los cuestionarios quedaron estructurados con 21 preguntas y un apartado de opiniones y sugerencias; la distribución asignada se presenta en el cuadro siguiente:

\begin{tabular}{|l|l|l|}
\hline Unidad Administrativa & Unidades & $\%$ \\
\hline
\end{tabular}


http://revistainvestigacionacademicasinf rontera.com

\begin{tabular}{|l|l|l|}
\hline $\begin{array}{l}\text { Administración } \\
\text { Desconcentrada de } \\
\text { Recaudación "1" de Baja } \\
\text { California }\end{array}$ & 13 & 61.90 \\
\hline $\begin{array}{l}\text { Administración } \\
\text { Desconcentrada Jurídica } \\
\text { "1" de Baja California }\end{array}$ & 9 & 38.10 \\
\hline
\end{tabular}

Es de mencionarse que el cuestionario está formado por lo siguiente:

I. Datos Generales.

II. Formación Académica

III. Conocimiento sobre las funciones de la Administración Local de Recaudación de Mexicali.

IV. Conocimiento sobre el Procedimiento Administrativo de Ejecución.

V. Conocimiento sobre la Garantía de Audiencia.

VI. Conocimiento sobre la Reforma Constitucional en Materia de Derechos Humanos.

Por la Administración Desconcentrada Jurídica "1" de Baja California participaron 9 Abogados dictaminadores, mientras que por la Administración Desconcentrada de Recaudación de Baja California "1" colaboraron 13 servidores públicos, en cuanto al grado de estudios de los censados, unos de los datos trascendentales fue que el $100 \%$ cuentan como mínimo licenciatura y el $14.28 \%$ cuanta con el grado en maestría, las 21 personas encuestadas manifestaron conocer las facultades con las que cuenta la unidad recaudatoria señalando entre las principales, la notificación, control y cobro de los créditos fiscales, el embargo, remate, avalúo y adjudicación de bienes. 


\section{http://revistainvestigacionacademicasinfrontera.com}

Respecto del conocimiento sobre la Garantía de Audiencia, resulta importante señalar que 3 de los censados ignoran el contenido de los artículos 14 y 16 de la Constitución Política de los Estados Unidos Mexicanos, 5 no conocen las formalidades esenciales del procedimiento, sin embargo existen abogados tributarios y abogados dictaminadores que desconozcan las formalidades esenciales del procedimiento pues cuando se les solito que mencionaran las mismas, respondieron lo siguiente: 2 no contestaron, 17 hablaron del Procedimiento Administrativo de Ejecución y 2 mencionaron la notificación, lo que demuestra que existe un amplio desconocimiento sobre las formalidades esenciales del procedimiento, no obstante lo anterior el $100 \%$ de los censados contestaros en sentido afirmativo que dichas formalidades deben ser respetadas y observadas estrictamente por la autoridad recaudadora al momento de desarrollar el procedimiento administrativo de ejecución.

Conocimiento de los artículos 14 y 16 Constitucionales 
http://revistainvestigacionacademicasinfrontera.com

\section{Artículos 14 y 16 de la Constitución}

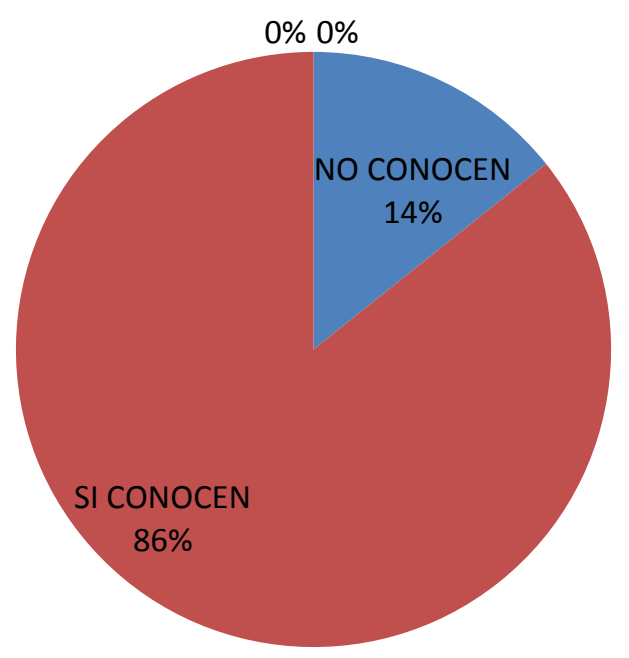

Conocimiento de las Formalidades Esenciales del Procedimiento

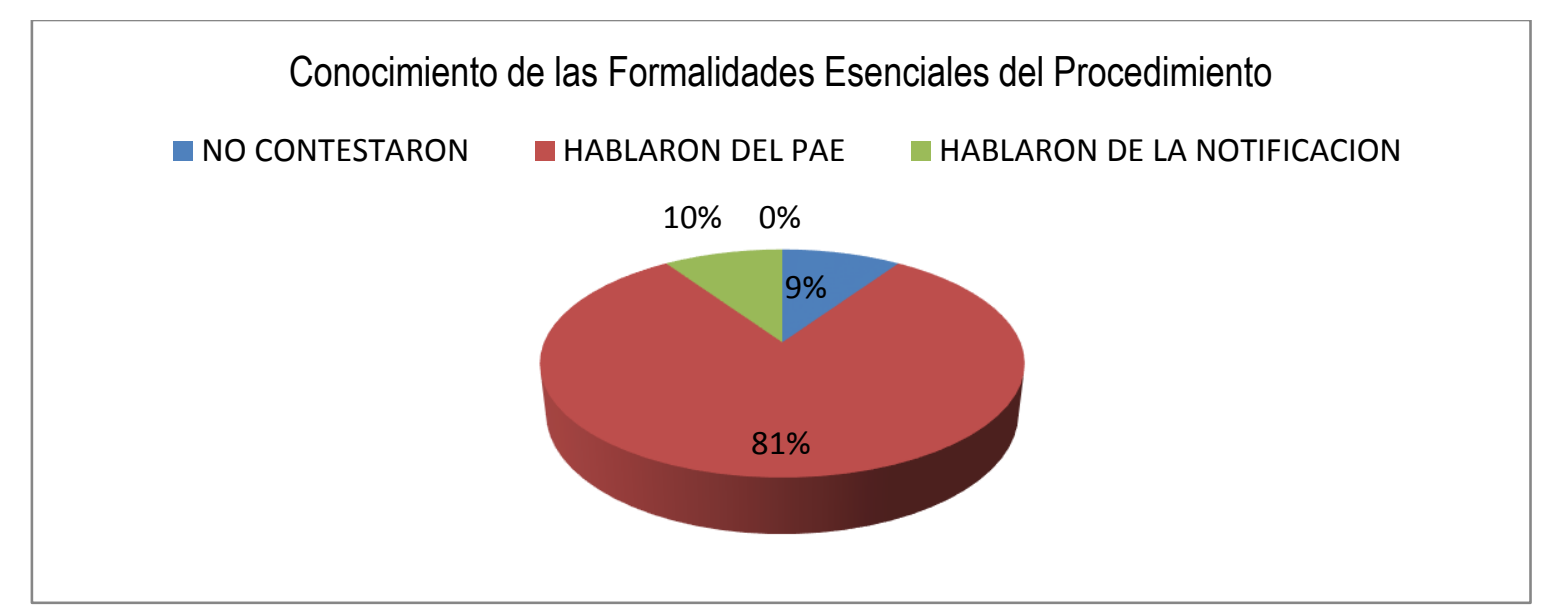

Respecto del conocimiento sobre la Reforma Constitucional del 10 de Junio de 2011 en materia de Derechos Humanos, es preciso señalar que el $61.90 \%$ de los censados no tienen conocimiento de que el 10 de Junio del año 2011 se reformó la Constitución Política de los Estados Unidos Mexicanos, ahora bien de los que 
Año 9. Núm. 24 (Edición especial Julio- diciembre 2016)

\section{http://revistainvestigacionacademicasinfrontera.com}

Revista de Investigación Académica sin Frontera ISSN: 2007-8870

contestaron que si tenían conocimiento sobre dicha reforma manifestaron lo siguiente: 2 no respondieron a la interrogante, 1 contesto que fue en materia fiscal, 2 en amparo y 8 en materia de Derechos Humanos, lo que da como resultado lo siguiente: el 61.90 no tiene conocimiento sobre la reforma constitucional en Derechos Humanos.

Conocimiento de la Reforma Constitucional

Conocimiento Sobre la Reforma Constitucional del 10 de Junio del 2011

NO LA CONOCEN - SI LA CONOCEN

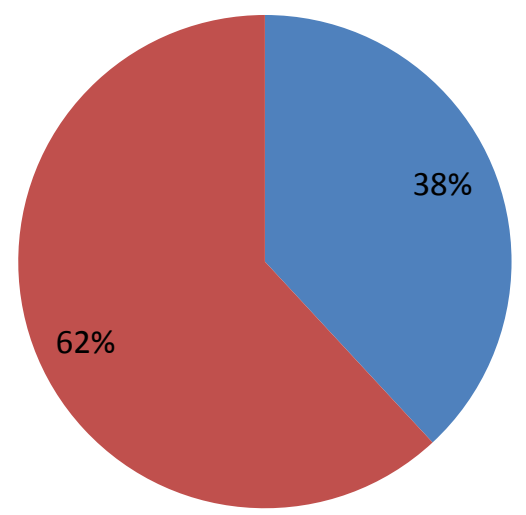

Materia de la Reforma Constitucional

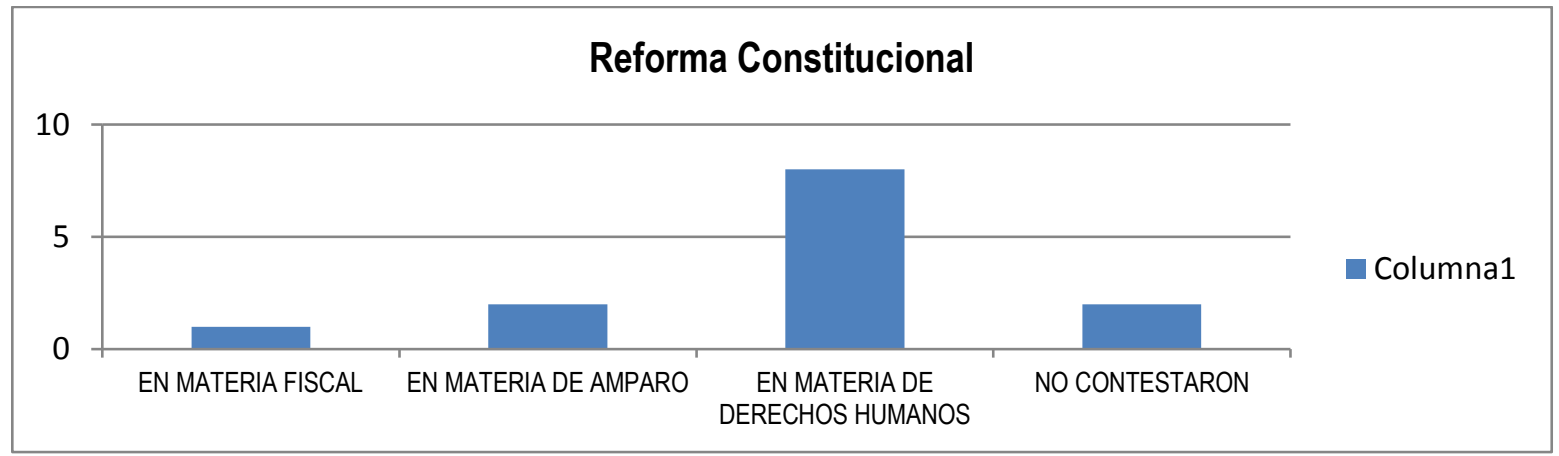


Año 9. Núm. 24 (Edición especial Julio- diciembre 2016)

\section{http://revistainvestigacionacademicasinfrontera.com}

Revista de Investigación

Académica sin Frontera

ISSN: 2007-8870

No obstante lo anterior, es importante hacer del conocimiento que de los censados el 47.61 considera que si se violan los Derechos Humanos del Contribuyente cuando se inmovilizan cuentas bancarias sin previa diligencia de requerimiento de pago y embargo, mismo porcentaje manifestó que la garantía violada es la de Garantía de Audiencia.

Ahora bien, respecto del embargo, remate y adjudicaciones de bienes muebles e inmuebles propiedad de terceros ajenos a la relación jurídico-tributaria, el $19.04 \%$ de los encuestados manifestaros que si se amedrentan Derechos Humanos a los Contribuyentes cuando esto ocurre, señalando el mismo porcentaje que la garantía vulnerada es la garantía de Audiencia y Seguridad Jurídica.

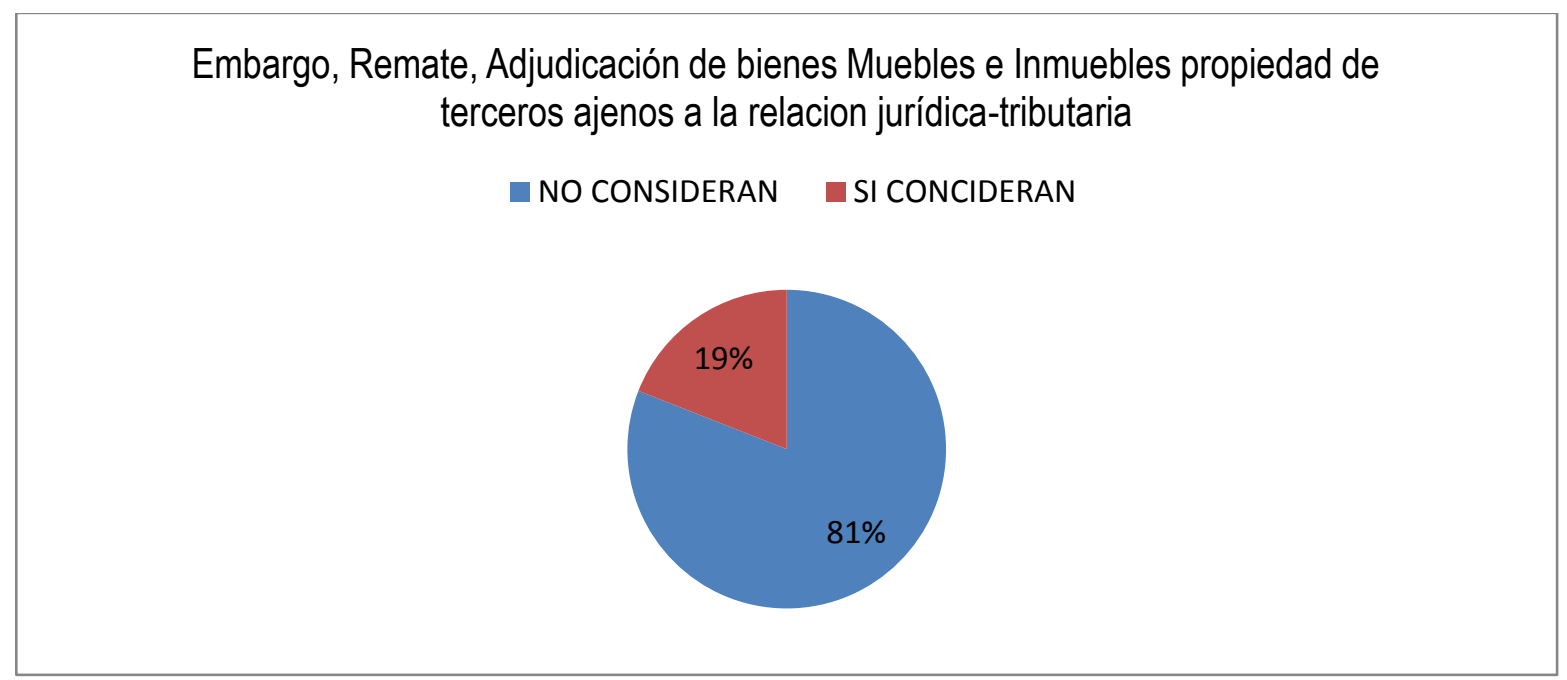

Es importante hacer mención, que en esta pregunta los abogados tributarios y abogados dictaminadores se basaron para contestar en el conocimiento jurídico que tienen respecto del Embargo en Vía Administrativa y los Responsables Solidarios que no son los supuestos de esta investigación, ya que en el presente trabajo, el supuesto de análisis son "los terceros ajenos", es decir los sujetos que no tienen 


\section{http://revistainvestigacionacademicasinfrontera.com}

Revista de Investigación Académica sin Frontera ISSN: 2007-8870

una relación ni directa ni indirecta con el deudor y el sujeto activo de la relación tributaria.

\section{CONCLUSIONES}

Primera: Es necesario un curso de actualización en Derecho Constitucional, donde se exponga el caso Rosendo Radilla Pacheco y la Reforma Constitucional en materia de Derechos Humanos, destinado a los abogados tributarios de la Administración Desconcentrada de Recaudación de Baja California "1" y a los abogados dictaminadores de la Administración Desconcentrada Jurídica de Baja California "1".

Segunda: Es necesario un curso de actualización sobre las partes que intervienen en la relación jurídico-tributaria, destinado a los Abogados Tributarios y a los Abogados Dictaminadores de las Unidades Administrativas del Servicio de Administración Tributaria de la Local de Recaudación y Jurídica de Mexicali.

Tercera: La Administración Desconcentrada de Recaudación de Baja California "1", conculca Derechos Humanos cuando embarga, remata y/o se adjudica bienes muebles e inmuebles de su propiedad de terceros ajenos a la relación jurídicotributaria.

Cuarta: Una vez que el contribuyente promueva recurso de revocación o tercería excluyente de dominio, la Administración Desconcentrada Jurídica de Baja California "1", debe dejar sin efectos los embargos, remates y/o adjudicación de los bienes muebles e inmuebles propiedad de personas ajenas a la relación jurídicotributaria, con fundamento en el Código Fiscal de la Federación y a la luz de la 


\section{http://revistainvestigacionacademicasinf rontera.com}

Reforma Constitucional del 10 de Junio de 2011, en razón de que se conculcan Derechos Humanos.

Quinta: La Administración Desconcentrada de Recaudación de Baja California “1”, puede tener una mejor eficacia en sus Procedimientos Administrativos de Ejecución, si realiza una investigación más minuciosa y detallada respecto de los bienes muebles e inmuebles que están afectos a dicho procedimiento.

Sexta: Hoy en día los desafíos y metas recaudatorias que le han fijado a la Administración Desconcentrada de Recaudación de Baja California "1" son muy elevadas, por lo que 13 abogados tributarios son muy pocos para satisfacer las necesidades de una circunscripción territorial que abarca Mexicali y su Valle, San Felipe, San Luis Rio Colorado, Puerto Peñasco y Sonoyta. Por lo que el Servicio de Administración Tributaria debe de invertir en plazas estables y remuneradas para responder a las expectativas planteadas.

Séptima: El erario público de la federación pierde ingresos por embargos, remates y/o adjudicaciones propiedad de terceros ajenos a la relación jurídico-tributaria, ya que los Jueces de Distrito del Decimoquinto Circuito a través de sus sentencias resuelven dejar sin efectos dichos actos de autoridad.

Octava: La Administración Desconcentrada de Recaudación de Baja California "1", con la finalidad de evitar violaciones procesales y constitucionales, debe girar oficios a los notarios públicos de Mexicali o bien al archivo general de notarías, para que estos informen si los bienes inmuebles afectos al Procedimiento Administrativo de Ejecución han sido materia de algún tipo de contrato. 
Año 9. Núm. 24 (Edición especial Julio- diciembre 2016)

\section{http://revistainvestigacionacademicasinfrontera.com}

Revista de Investigación

Académica sin Frontera ISSN: 2007-8870

\section{Fuentes Consultadas}

Astudillo, M. M. (2002). Algunas consideraciones sobrela nueva hacienda pública. Momento Económico, 19.

De la Garca, S. F. (2005). Derecho Financiero . México: Porrúa.

Domingo Hernández, C. T. (2004). Sobre la Reforma Tributaria en México. Economía UNAM, 47.

Formalidades Esenciales del Procedimiento. Son las que garantizan una adecuada y oportuna defensa previa al acto privativo., 200234 (Pleno de la Suprema Corte de Justicia de la Nación 23 de Noviembre de 1995).

Ocampo Medina, C. (2012). Origen y Evolución del SAT. Puntos Finos edición especial, 24.

Persona Extraña a Juicio, Concepto de., 196932 (Pleno del Tercer Circuito 13 de Enero de 1998).

Rodríguez Lobato, R. (2006). Derecho Fiscal . México : Oxford .

Sánchez Gómez, N. (2011). Derecho Fiscal Mexicano . México: Porrúa . 